Published in final edited form as:

Curr Opin HIV AIDS. 2011 July ; 6(4): 315-325. doi:10.1097/COH.0b013e32834788e7.

\title{
HIV-1 treatment as prevention: the good, the bad, and the challenges
}

\author{
Kumi Smith ${ }^{a}$, Kimberly A. Powers ${ }^{a, b}$, Angela D.M. Kashubac ${ }^{c}$, and Myron S. Cohen ${ }^{a, b, d}$ \\ aDepartment of Epidemiology, University of North Carolina \\ bDepartment of Medicine, University of North Carolina \\ 'Eshelman School of Pharmacy, University of North Carolina, Chapel Hill, North Carolina, USA \\ ${ }^{d}$ Department of Microbiology and Immunology, University of North Carolina, Chapel Hill, North \\ Carolina, USA
}

\begin{abstract}
Purpose of review-This work focuses on the use of antiretroviral agents to prevent the sexual transmission of HIV-1.

Recent findings-Two randomized clinical trials demonstrated that antiretroviral agents provided before exposure to HIV-1 offer substantial protection, ostensibly directly proportional to the concentration of antiretroviral therapy (ART) in the genital secretions. Intense focus on the use of HIV treatment as prevention has led to publication of modeling exercises, ecological studies, and observational studies, most of which support the potential benefits of ART. However, the logistical requirements for successful use of ART for prevention are considerable.
\end{abstract}

Summary-ART will serve as a cornerstone of combination prevention of HIV-1. Continued research will be essential to measure anticipated benefits and to detect implementation barriers and untoward consequences of such a program, especially increases in primary ART resistance.

\section{Keywords}

antiretroviral therapy; pre-exposure prophylaxis; prevention

\section{Introduction}

Literally days after the activity of the first antiretroviral agent, azidothymidine (AZT), was announced, investigators began to explore the idea of treatment as prevention [1]. The promise of this approach is based on the idea that treatment of HIV index cases with antiretroviral therapy (ART) will reduce their viral loads and render them less infectious to their sexual partners. Several obvious challenges to this approach soon surfaced: would the preventive potential of AZT and other drugs be limited by low concentrations in the genital tract or by the development of drug resistance?

This article offers both a historical perspective and a more in-depth, contemporaneous view of the role of HIV-1 treatment as part of secondary HIV prevention. Current evidence suggests that this strategy holds great promise, but considerable research efforts will be 
required to employ the right antiretroviral agents at the right times - and perhaps to just the right people - to ensure maximal benefit both for individual 'couples' and at the population level.

\section{The clinical pharmacology of HIV prevention}

Two studies published in 2010 demonstrate the ability of ART to prevent HIV acquisition. In the Center for the AIDS Program of Research in South Africa (CAPRISA) 004 study, women at risk of acquiring HIV were randomly assigned to receive either a tenofovir (TFV) containing vaginal gel or a placebo using coitally dependent dosing [2•]. In the PreExposure Prophylaxis Initiative (iPREX) study, at-risk MSM were randomly assigned to receive either a tablet containing tenofovir disoproxil fumarate (TDF) with emtricitabine (TDF + FTC) or placebo dosed daily [3•]. In both trials, rates of HIV acquisition were lower in those receiving the antiretrovirals. In CAPRISA 004, an inverse relationship was noted between drug exposure in the vaginal lumen and risk of infection. As the CAPRISA 004 study measured drug exposure at the site of infection, and as the half-life of topically applied TFV in the genital tract is more than 2 days, these investigators are conducting subsequent analyses to determine whether critical exposures for protection of mucosal tissue in the genital tract can be identified. As iPREX study only measured plasma drug exposure, it is less likely that concentration surrogates can be estimated for rectal mucosal protection from these data. However, both types of concentration measures may be used as surrogates for adherence behavior, which is critical to the success of prevention interventions [4].

For treatment of the index case, the relative ability of different antiviral agents to penetrate mucosal surfaces at the site of transmission is critical for full suppression of HIV replication $[5,6]$. Drugs both within and between therapeutic classes of antiretrovirals have different potential to concentrate in male and female genital tract secretions and in rectal tissue (Table 1) $[5]$.

\section{The female genital tract}

The female genital tract exposure to 20 antiretrovirals has been studied in cervicovaginal fluid. Although the female genital tract contains upper and lower compartments, analyzing this fluid (a combination of cervical mucus and vaginal fluid) is a noninvasive approach to understanding genital tract pharmacology. As can be seen in Table 1, there is significant variability in drug exposure both within and between antiretroviral classes. To date, no physicochemical properties accurately predict drug penetration into cervicovaginal fluid. Of the nucleoside/ tide analog reverse transcriptase inhibitors (NRTIs), TDF zidovudine (ZDV), FTC, and lamivudine (3TC) achieve concentrations of approximately 100-400\% higher than that of blood plasma. Of the non-NRTIs (NNRTIs), only etravirine (ETR) demonstrates concentrations similar to, or higher than, that of blood plasma. For the protease inhibitors, indinavir (IDV) and darunavir (DRV) penetrate cervicovaginal fluid at exposures of approximately 150-200\% higher than that of blood plasma. Finally, both drugs in the latest Food and Drug Administration (FDA)-approved therapeutic classes of antiretrovirals (coreceptor antagonists and integrase inhibitors) concentrate in cervicovaginal fluid: raltegravir (RAL) exposure is approximately $200 \%$ higher than that of blood plasma, and maraviroc (MVC) exposure is approximately $400 \%$ higher than that of blood plasma. Investigators also measured the protein binding of MVC in cervicovaginal fluid and determined that it had 10 -fold less protein binding than in plasma (7.5 versus 75\%) [7]. As less protein binding results in more amount of drug available for antiviral activity, this phenomenon must be considered in pharmacokinetic-pharmacodynamic analysis of antiretroviral prevention strategies. 
Finally, tissue concentrations of TFV, FTC, and MVC have been measured in the vagina and cervix $[7,8]$. Exposures for all of these drugs fall between those concentrations measured in blood plasma and those in cervicovaginal fluid. This information creates insight into drug distribution in the genital tract and demonstrates that noninvasive sampling of cervicovaginal fluid may be a reasonable surrogate for these concentrations, which can only be measured through invasive sampling methods.

\section{The male genital tract}

Although the male genital tract contains a number of subcompartments (testes, prostate, and seminal vesicles), drug concentrations are typically measured in seminal plasma as an overall marker of drug exposure. Data generated, to date, reveal that drug binding to plasma proteins dictates drug exposure in semen: lower semen concentrations are found with drugs that have higher protein binding [5].

NRTIs, which are generally less than $50 \%$ protein bound, achieve exposures in semen ranging from approximately 100 to $600 \%$ of those observed in blood plasma [6]. However, these drugs must be phosphorylated intracellularly in order to be active. After oral administration of TDF, intracellular mononuclear tenofovir diphosphate (TFV-DP) concentrations in the semen are at least $800 \%$ higher than that in peripheral blood mononuclear cells [9]. This increased extracellular-intracellular relationship in semen does not hold for the two other nucleosides investigated to date: ZDV and 3TC. Despite four-fold to six-fold higher concentrations in seminal plasma, intracellular mononuclear cell concentrations of ZDV triphosphate (ZDV-TP) in semen are $40 \%$ of those in peripheral blood mononuclear cells, and mononuclear cell concentrations of 3TC-TP in semen are approximately $100 \%$ of those in peripheral blood mononuclear cells [10]. These data illustrate the importance of quantifying intra-cellular drug exposure to develop accurate pharmacokinetic-pharmacodynamic models for HIV prevention. Exposure of the NNRTIs in semen ranges from undetectable to $40 \%$ lower than plasma exposure, whereas the majority of protease inhibitor concentrations are more than $80 \%$ lower than the blood plasma concentration (the exception is IDV, which is $60 \%$ protein bound). RAL concentrations are approximately $150-600 \%$ higher in semen than that in blood plasma [11]. MVC semen exposure was recently determined to be $40 \%$ lower than that in blood plasma. However, due to low protein binding in the semen, protein-unbound (active) MVC concentrations were still 28 -fold higher than the protein-free $\mathrm{IC}_{90}$ for $\mathrm{HIV}$ wild-type virus [8].

\section{Rectal mucosal tissue}

The extent of penetration of drugs into rectal tissues also has implications for HIV transmission. Exposures (area under the concentration time curve from 0 to tau, or $\mathrm{AUC}_{0 \text {-tau }}$ ) of MVC are approximately 30 times higher in rectal tissues than in plasma [12], whereas exposures of DRV, ritonavir, and ETR are approximately 3, 13, and 7 times higher, respectively, in rectal tissue than in plasma [13]. Some drugs, such as the nucleoside/tide analogs, require cellular uptake and phosphorylation in order to be active. Intracellular and extracellular concentrations of TFV and FTC have been recently measured in plasma and in rectal tissues 1-14 days after a single dose [14]. TFV and FTC exposures $\left(\mathrm{AUC}_{\text {day } 1-14}\right)$ were 34 and four times higher in rectal tissues, respectively, than in blood plasma. Intracellular concentrations of TFV-DP were detected for 14 days in rectal tissue, whereas FTC triphosphate (FTC-TP) was detected for only 2 days after dosing. These data demonstrate that, as with genital tract exposure, antiretroviral rectal tissue exposure varies between and within drug class. Selecting those antiretrovirals with favorable extracellular and intracellular pharmacokinetics may eliminate viral shedding from mucosal surfaces implicated in HIV transmission. 


\section{Viral shedding}

However, even when the blood viral burden is suppressed, HIV can be recovered from the male and female genital tract [15-19]. In an unpublished review of 51 identified studies of HIV shedding in the female genital tract, all 31 studies that measured shedding in individuals receiving ART found that suppression in the female genital tract was incomplete [15]. In the most careful study to date, Cu-Uvin et al. [20•] found that among women with completely suppressed plasma and genital tract viral loads at baseline, $54 \%$ had detectable genital tract viral loads during at least 1 monthly visit over the 1-year follow-up period. In $32 \%$ of these women, the genital tract viral loads were detectable at a visit when viremia was suppressed, suggesting that some women with undetectable blood viral loads may maintain a high risk of onward transmission.

Two reviews of viral shedding in the male genital tract collectively identified 22 studies of HIV-RNA persistence in the semen of men receiving ART, despite undetectable blood plasma viral load $[15,16]$. The most notable among them, by Sheth et al. [21], involved longitudinal assessments of paired blood plasma and seminal plasma samples from HIVinfected men starting first-line ART. Among the 13 men who were on prolonged combination ART (cART) with fully sustained viral suppression in blood plasma, four were found to have detectable viral load in seminal plasma. Moreover, the investigators did not find a significant association between isolated semen HIV-RNA shedding and local level of any drug.

In addition to concerns about continued transmission from individuals with suppressed viremia, a substantial number of new (untreated) patients present with HIV resistance to one or more classes of antiretroviral agents [22•,23-25]. Transmitted drug resistance (primary resistance) must reflect transmission from people who are partially treated, people who stopped their treatment, or resistant variants in the genital tract. Patterns of resistance in the genital tract correspond with observed antiretroviral drug exposure in genital excretions. For example, the presence of protease-resistant viral isolates in seminal plasma and vaginal fluid may be related to the poor penetration of protease inhibitors into the genital tract [5]. As antiretrovirals achieving higher exposure in the genital tract are likely to have a greater ability to reduce viral loads in genital compartments, improved understanding of drug penetration into the genital tract could help guide therapy choices.

Translation of these results into public health considerations is more complex. Viral replication in both the female and male genital tract can be independent of the blood [26•], so different variants can be recovered, regardless of the treatment. The transmission potential of these variants, or variants shed in spite of treatment, is unknown. However, virologic comparisons in HIV transmission pairs suggest considerable selection during the HIV transmission event [27]. Careful studies of transmitted drug resistance suggest that some mutations may render viral variants less fit for transmission. For example, multiple resistant variants are less likely to occur than single variants, and among single resistant variants $[28 \cdot, 29-31]$.

\section{Antiretroviral therapy, public health, and observational studies}

Two kinds of observational studies have been used to support the ability of ART to reduce transmission of HIV: studies of HIV-serodiscordant couples and ecological studies of community populations.

\section{Serodiscordant couples studies}

Observational studies of seroconcordant and discordant couples provide a critical window into the details of HIV-1 transmission. Eyawo et al. [32•] have provided an exhaustive 
review of discordant couples studies in South Africa, designed to understand whether the male or female partner is more likely to remain uninfected. The complexity of this team's research helps us identify barriers to valid estimations of transmission probabilities. First, not all partners are equally susceptible to HIV; therefore, some partners can remain HIVnegative regardless of the infectivity of their sexual partner. Second, the infectivity of the index case at the time of sexual contact depends primarily on the viral load, which is generally not known and can be highly variable. Third, using the tools of molecular virology, it has become clear that transmission events in 10-30\% of couples likely involve a third partner [33,34], with only a minority of new HIV infections taking place within identifiable stable relationships [35•].

These concerns notwithstanding, observational studies offer the most compelling evidence that ART can be expected to prevent HIV-1 transmission. More than a decade ago, a series of reports linked the blood viral load of untreated index cases with the probability of HIV transmission to their partners [36,37]. Obviously, in these studies the blood viral load must serve as a surrogate for the genital tract HIV-1 concentration. In the most widely cited study, from Rakai, Uganda, index case viral load was the chief predictor of heterosexual HIV transmission risk [36]. The authors found that the mean viral load of infected individuals who transmitted the virus to their partners was significantly higher than that of nontransmitters (90 254 versus $38029 \mathrm{copies} / \mathrm{ml}$ ) and that no transmissions occurred in couples in whom the infected partner's viral load was under 1500 copies $/ \mathrm{ml}$. Observational studies of HIV-discordant couples in Zambia, Spain, Thailand, and the USA uphold these findings [38-40].

Other observational studies have demonstrated reduced HIV transmission when ART in the index case reduced the patient's viral load (at least theoretically); those with information on ART distribution in the index cases are shown in Table $2[41,42 \bullet, 43-48,49 \bullet]$. Bunnell et al. [50] estimated that ART was associated with a $98 \%$ reduction in the incidence of HIV in heterosexuals, from 43.5 to 0.8 cases per 1000 person-years, and Donnell et al. [43] found that only one of 103 genetically linked HIV transmission events in their cohort of 3381 couples occurred in a couple in which the index case was receiving ART, corresponding to a $92 \%$ reduction. A similar study of 424 couples in Spain found that none of the partners of treated HIV-infected individuals seroconverted, whereas five of those whose index case was not treated did $[42 \bullet]$.

Several other studies, however, suggest that the protective effects of ART on sexual HIV transmission may not be as consistent or absolute. Out of the 26 seroconversions in nonindex partners of $436 \mathrm{HIV}$-discordant couples in Italy, for example, six took place in couples in whom the HIV-infected partner was receiving AZT at the time [46]. More recently, Sullivan et al. [48] found that ART in the index case of cohorts in Rwanda and Zambia was associated with a 94\% reduction in HIV transmission, but noted that ART failed to completely eliminate risk, as four seroconversions took place when the index partner was on ART. Finally, investigators in China recently documented 84 transmission events in a cohort of 1927 discordant couples in which over 70\% of index cases were receiving ART. Interestingly, the authors found no statistical difference in the seroconversion rates between those whose HIV-positive partner was receiving ART (66 of 1369 or $4.8 \%$ ) and those whose spouse was not (18 of 558 or $3.2 \%, P=0.12$ ). Participants in the study reported extremely low rates of extramarital sex and drug use, and those who reported irregular condom use in the past month were 12.64 times as likely to seroconvert (95\% confidence interval 8.1819.75). Findings from the Chinese cohort suggest that heterosexual transmission of HIV may persist even in populations with high treatment coverage [49•]. 


\section{Ecological studies of community-level benefit}

Studies of HIV incidence and prevalence in populations or communities with ready access to ART have been used to argue that treatment is prevention. Studies from San Francisco $(n=$ 3 studies) [51 $, 52,53]$, Taiwan $(n=1)$ [54], and British Columbia $(n=3)[55,56,57 \bullet]$ argue that the introduction of ART reduced the expected number of cases of HIV. These studies are all limited in several ways: it is difficult if not impossible to prove that the treated group has actually had contact with the at-risk population; none of these studies report changes in actual incidence of HIV, but rather use HIV prevalence or new cases of HIV detected (San Francisco and British Columbia) as a surrogate for incidence [58]. Indeed, when a more realistic measure of incidence was measured in San Francisco (using an assay of limited sensitivity) no difference could be ascribed to ART [57•]; and these studies are all subject to the 'ecologic fallacy,' as falling prevalence of HIV-1 could reflect any number of factors unrelated to the availability of ART [59•].

Furthermore, other studies have come to less optimistic conclusions about the populationlevel benefits of ART. For example, three analyses of data from MSM in Amsterdam reported evidence of a renewed spread of rectal gonorrhea and early syphilis since the 1990s $[60,61,62 \cdot]$, suggesting that sexual risk compensation may outweigh the benefits of treatment. Another found that recent HIV transmission among MSM in Sydney persisted at rates comparable with the pre-highly active ART era in spite of undetectable viral load among a large portion of treated HIV-infected men [63•]. A number of modeling studies have also suggested that wide availability of ART has not had a profound effect on HIV incidence $[64,65,66 \bullet]$. Although it is possible that new infections are attributable to transmissions during acute/ early infection or increased risk due to untreated sexually transmitted infections (STIs), the mixed results of these studies underscore the speculative nature of the treatment as a prevention strategy.

\section{Mathematical modeling}

Perhaps nothing has caused more confusion than the plethora of mathematical models purporting the benefits (and sometimes cost) of treatment as prevention. Substantial uncertainty surrounds many central assumptions: does ART actually reduce HIV transmission at the level of the couple, and by how much; how durable is the suppression of transmission; how many people can be detected and treated, and for how long; and what role does amplified transmission play, especially during acute/ early HIV infection.

We have recently summarized at least some of the mathematical models [67], and an exhaustive review is beyond the scope of this article. In addition, Current Opinion in HIV and AIDS devoted an entire recent issue to modeling, which highlighted advances and discussed trade-offs between model complexity and real-world relevance $[68,69]$. To some extent, the enthusiasm for treatment as prevention is driven by Utopian modeling: if you assume you can find almost all of the HIV-infected people, and you treat them all for life, and acute/early infection is only modestly important, and treatment reliably and durably suppresses HIV transmission, then the epidemic can be modeled away [70]. And if everyone benefits from earlier treatment, elimination of the epidemic can be achieved at a tolerable cost. However, by using more conservative assumptions and accounting for possible behavioral changes due to perceived noninfectiousness, other models have found that ART scale-up might be ineffective or in some cases even worsen the spread of HIV [71,72,73•, 74-]. Additionally, the cost can become exorbitant. In the most recent model, Long et al. [75•] argued that even with optimistic assumptions about infectivity reductions, ART coverage, and behavior change (and even without accounting for heightened infectivity during acute HIV), annual test-and-treat programs are unlikely to result in HIV elimination in the USA without additional measures. 


\section{Clinical trials}

We are aware of only a single clinical trial designed to demonstrate that HIV treatment prevents secondary HIV transmission. In the ongoing HPTN052 study of more than 1800 HIV-1-discordant couples in whom the infected person has a high baseline CD4 cell count (>350-550 cells/ $\mu \mathrm{l}$ ), index cases have been randomized to immediate versus deferred (beginning at CD4 >250) treatment arms, with 5 years of active follow-up. The primary end point is the magnitude and durability of the prevention benefit of ART, based on the measurement of virally linked transmission events. In addition, the study will measure the benefit of earlier ART for the health of the index case. The study is approximately 50\% complete. During the course of this trial, WHO changed their treatment guidelines to suggest that all patients be treated at CD4 cell counts of more than 350 cells/ $\mu 1$ [76], based on a 'moderate' level of evidence deduced from two observational trials [77,78]. After careful consideration of all evidence and the trial design, the multinational DSMB that oversees HPTN052 study concluded that the trial should continue unchanged.

It should be emphasized that this trial is designed to measure HIV prevention under idealized conditions and to provide healthcare providers with the most accurate information to pass on to their patients, especially discordant couples. In 2008, the Swiss AIDS commission issued a statement indicating the belief that patients treated - under circumstances in which viral load suppression has been demonstrated - could safely engage in unprotected intercourse [79]. Following the controversial statement, investigators in Switzerland, some of whom were authors of the original Swiss statement, found that unprotected sex among HIV-1-infected patients on ART may have in fact increased in the wake of the announcement [80]. The Swiss cohort reminds us that perceptions of infectiousness among patients are highly impressionable and that the use of ART for prevention must address efficacy at both the individual and population level [81]. The results of HPTN052 study will likely provide more precise information to people with HIV-1 infection and their sexual partners.

\section{Test and treat}

Given that treatment reduces transmission at some level, tremendous interest in a 'test and treat' strategy has emerged and has been embraced by at least some professional organizations. This strategy requires widespread, regular HIV testing; linkage to care; and immediate treatment (irrespective of CD4 cell counts). Because none of these strategies have actually been implemented - let alone proven of benefit - a series of feasibility trials have been planned or launched, as summarized in Table 3.

An alternative approach would lead to targeting of HIV-infected patients with the greatest risk of HIV transmission. Investigators in Botswana have modeled the benefit of a strategy designed to find and treat patients with the highest viral load [82]. It has long been known that patients with clade C HIV infection can sustain very high viral loads in blood and genital secretions [83]. In addition, clade $\mathrm{C}$ variants retain the R5 phenotype even in advanced HIV disease, perhaps amplifying transmission [84]. In more recent work, Novitsky et al. [82] demonstrated the ability to find and follow patients with high plasma HIV-1-RNA levels ( 250000 copies/ml). Among 4348 drug-naive, HIV-positive individuals participating in clinical studies in Botswana, a greater proportion of those in cART-initiating cohorts had high viral loads than did those in general population cohorts, and the median baseline plasma HIV-1-RNA level was higher in the cART-initiating cohorts by approximately $1 \log _{10}$. Additionally, in a longitudinal analysis of 42 seroconverters, the median duration of high viral loads was 350 days following seroconversion, with $33 \%$ of participants maintaining high viral loads for at least 180 days. On the basis of these 
observations, and assuming that individuals who maintain high plasma viral loads for extended periods contribute disproportionately to onward transmission, the authors suggested that a modified test-and-treat approach with targeted ART initiation could have the potential to mitigate the HIV epidemic in some settings.

\section{The problem of acute and early HIV infection}

The acquisition of HIV is associated with a complex illness designated as acute HIV-1. During this phase, viral replication is unrestrained by host response, and irreparable immune damage occurs. Several lines of evidence demonstrate that people with early HIV infection are more contagious than those with chronic HIV infection. The contribution of early infection to the spread of HIV has been extensively modeled and reviewed in detail [85]. Results have varied widely, reflecting the differences in assumptions used, data available, and populations studied. For example, an early model of HIV transmission among MSM in the USA that did not confine transmission to steady partnerships estimated that up to $50 \%$ of incident infections were due to contact with an index case with early HIV [86]. By contrast, a model of HIV transmission in Uganda that assumed sexual contact occurred only within monogamous heterosexual pairs estimated that $9 \%$ of transmission events were attributable to early index cases [87]. In a recent study from Malawi, Powers et al. [88] used a model that allowed transmission both within and outside of steady pairs to estimate that $38 \%$ of all incident cases of HIV can be ascribed to exposure to a person with early HIV infection. Epidemiologic evidence further supports the importance of early/acute HIV in onward transmission. For example, Hightow et al. [89] reported that 12 of 84 patients with newly diagnosed HIV infection in North Carolina had acute HIV infection, suggesting the importance of these individuals to the sexual network the authors described.

Obviously, the benefits of the 'test and treat' strategy will be reduced by the extent that early HIV contributes, unless such individuals can be detected and secondary transmission reduced. However, no strategies to prevent transmission of HIV from those with acute/early HIV have been developed. In a recent report, Pettifor et al. [90] noted the difficulty of behavior change in such individuals. The use of ART during acute/early HIV infection either for personal or public health benefit -is controversial [91].

\section{Conclusion}

It has become clear that HIV prevention requires a combined prevention effort, and the use of antiretroviral agents will serve as a cornerstone of this effort. The demonstration that ART can be used as pre-exposure prophylaxis is not surprising and is consistent with the ability of these drugs to block replication of HIV-1. We can also expect treated patients to be less contagious, as long as they remain suppressed. However, the replication of HIV-1 in the genital compartment in spite of viral suppression in blood motivates the ongoing research designed to understand the magnitude and durability of HIV treatment as prevention. Finally, challenges remain in defining the optimum strategy for using treatment as prevention, finding the most contagious people, and providing both personal and public health care. The extent to which we can meet these challenges will determine the success of the 'test and treat' strategy.

\section{References and recommended reading}

Papers of particular interest, published within the annual period of review, have been highlighted as:

- of special interest 
$\bullet$ of outstanding interest

Additional references related to this topic can also be found in the Current World Literature section in this issue (p. 338).

1. Henry K, Chinnock BJ, Quinn RP, et al. Concurrent zidovudine levels in semen and serum determined by radioimmunoassay in patients with AIDS or AIDS-related complex. JAMA. 1988; 259:3023-3026. [PubMed: 3163381]

2. Abdool Karim Q, Abdool Karim SS, Frohlich JA, et al. Effectiveness and safety of tenofovir gel, an antiretroviral microbicide,for the prevention of HIV infection in women. Science. 2010; 329:11681174. [PubMed: 20643915] This study is the first to report the results of a clinical trial demonstrating the effectiveness and safety of a $1 \%$ vaginal gel formulation of TDF for the prevention of HIV acquisition in women. Results show that the gel reduces HIV acquisition by an estimated $39 \%$ overall and by $54 \%$ in women with high gel adherence.

3. Grant RM, Lama JR, Anderson PL, et al. Preexposure chemoprophylaxis for HIV prevention in men who have sex with men. N Engl J Med. 2010; 363:2587-2599. [PubMed: 21091279] This study is the first to report the results of a clinical trial demonstrating the efficacy of oral preprophylactic effect (iPREX) in preventing HIV among MSM in Asia and Africa. More information is needed to evaluate possible subclinical effects such as low-level drug resistance as well as potential adjustments in HIV risk behavior among users.

4. Michael NL. Oral preexposure prophylaxis for HIV: another arrow in the quiver? N Engl J Med. 2010; 363:2663-2665. [PubMed: 21091280]

5. Nicol MR, Kashuba AD. Pharmacologic opportunities for HIV prevention. Clin Pharmacol Ther. 2010; 88:598-609. [PubMed: 20881955]

6. Cohen MS, Gay C, Kashuba AD, et al. Narrative review: antiretroviral therapy to prevent the sexual transmission of HIV-1. Ann Intern Med. 2007; 146:591-601. [PubMed: 17438318]

7. Dumond JB, Patterson KB, Pecha AL, et al. Maraviroc concentrates in the cervicovaginal fluid and vaginal tissue of HIV-negative women. J Acquir Immune Defic Syndr. 2009; 51:546-553. [PubMed: 19546811]

8. Patterson, K.; Prince, H.; Kraft, E., et al. Exposure of extracellular and intracellular tenofovirandemtricitabine in mucosal tissues after a single fixed dose of TDC/ FTC: implications for preexposure HIV prophylaxis (PrEP); 18th International AIDS conference; Vienna, Austria. 2010.

9. Vourvahis M, Tappouni HL, Patterson KB, et al. The pharmacokinetics and viral activity of tenofovir in the male genital tract. J Acquir Immune Defic Syndr. 2008; 47:329-333. [PubMed: 18197124]

10. Dumond JB, Reddy YS, Troiani L, et al. Differential extracellular and intracellular concentrations of zidovudine and lamivudine in semen and plasma of HIV-1-infected men. J Acquir Immune Defic Syndr. 2008; 48:156-162. [PubMed: 18360288]

11. Bonora, S.; D'Avolio, A.; Simiele, M., et al. Steady-state raltegravir penetration in seminal plasma of healthy volunteers; 17th Conference on Retroviruses and Opportunistic Infections; San Francisco, California. 2010.

12. Brown, K.; Patterson, K.; Malone, S., et al. Antiretrovirals for prevention: maraviroc exposure in the semen and rectal tissue of healthy male volunteers after single and multiple dosing; 17 th Conference on Retroviruses and Opportunistic Infections; San Francisco, California. 2010.

13. Brown, KC.; Patterson, KB.; Jennings, SH., et al. Antiretrovirals for HIV prevention: darunavir + low dose ritonavir and etravirine exposure in the rectal tissue and seminal plasma of healthy male volunteers after single and multiple dosing; 18th Annual Conference on Retroviruses and Opportunistic Infections; Boston, Massachusetts. 2011.

14. Fletcher P, Harman S, Azijn H, et al. Inhibition of human immunodeficiency virus type 1 infection by the candidate microbicide dapivirine, a nonnucleoside reverse transcriptase inhibitor. Antimicrob Agents Chemother. 2009; 53:487-495. [PubMed: 19029331]

15. Brown, L.; Poole, C.; Patterson, K.; Cohen, M. Variability in female genital tract shedding and plasma viral loads: a systematic review; 17th International AIDS Conference; 3-8 August 2008; Mexico City. 
16. Chan DJ. Pathophysiology of HIV-1 in semen: current evidence for compartmentalization and penetration by antiretroviral drugs. Current HIV Res. 2005; 3:207-222.

17. Le Tortorec A, Dejucq-Rainsford N. HIV infection in the male genital tract: consequences for sexual transmission and reproduction. Int J Androl. 2010; 33:e98-e108. [PubMed: 19531082]

18. Diem K, Nickle DC, Motoshige A, et al. Male genital tract compartmentalization of human immunodeficiency virus type 1 (HIV). AIDS Res Hum Retroviruses. 2008; 24:561-571. [PubMed: 18426336]

19. Philpott S, Burger H, Tsoukas C, et al. Human immunodeficiency virus type 1 genomic RNA sequences in the female genital tract and blood: compartmentalization and intrapatient recombination. J Virol. 2005; 79:353-363. [PubMed: 15596829]

20. Cu-Uvin S, DeLong AK, Venkatesh KK, et al. Genital tract HIV-1 RNA shedding among women with below detectable plasma viral load. AIDS. 2010; 24:2489-2497. [PubMed: 20736815] This study determines patterns of genital tract HIV-1-RNA shedding over time among women with suppressed plasma viral load on ART.

21. Sheth PM, Kovacs C, Kemal KS, et al. Persistent HIV RNA shedding in semen despite effective antiretroviral therapy. AIDS. 2009; 23:2050-2053. [PubMed: 19710596]

22. Paredes R, Lalama CM, Ribaudo HJ, et al. Preexisting minority drug-resistant HIV-1 variants, adherence, and risk of antiretroviral treatment failure. J Infect Dis. 2010; 201:662-671. [PubMed: 20102271] This study of the relationship between minority drug-resistant human HIV-1 and virologic failure in treated patients finds that in adherent patients, pre-existing minority Y181C mutants more than triple the risk of virologic failure of first-line efavirenz-based ART.

23. Johnson JA, Li JF, Wei X, et al. Minority HIV-1 drug resistance mutations are present in antiretroviral treatment-naive populations and associate with reduced treatment efficacy. PLoS Med. 2008; 5:e158. [PubMed: 18666824]

24. Metzner KJ, Rauch P, von Wyl V, et al. Efficient suppression of minority drug-resistant HIV type 1 (HIV-1) variants present at primary HIV-1 infection by ritonavir-boosted protease inhibitorcontaining antiretroviral therapy. J Infect Dis. 2010; 201:1063-1071. [PubMed: 20196655]

25. Toni TA, Asahchop EL, Moisi D, et al. Detection of human immunodeficiency virus (HIV) type 1 M184V and K103N minority variants in patients with primary HIV infection. Antimicrob Agents Chemother. 2009; 53:1670-1672. [PubMed: 19171798]

26. Anderson JA, Ping LH, Dibben O, et al. HIV-1 populations in semen arise through multiple mechanisms. PLoS Pathog. 2010; 6 e1001053. This study compared HIV sequences in blood and semen using single gene amplification, a method that allows sensitive discrimination of these biological compartments. The results demonstrated that in some patient, blood and semen harbored similar viral variants, but that considerable divergence was possible. In addition, duplication of variants was observed in semen isolates, emphasizing ongoing viral replication in a closed compartment.

27. Derdeyn CA, Decker JM, Bibollet-Ruche F, et al. Envelope-constrained neutralization-sensitive HIV-1 after heterosexual transmission. Science. 2004; 303:2019-2022. [PubMed: 15044802]

28. Harrison L, Castro H, Cane P, et al. The effect of transmitted HIV-1 drug resistance on pretherapy viral load. AIDS. 2010; 24:1917-1922. [PubMed: 20588166] In this study, the authors demonstrate detection of transmitted variants with drug resistance markers. They note that individuals infected with the M184 V/l variant had lower blood viral load, which they argue reflects a replication fitness cost associated with the mutation.

29. Murillo W, Paz-Bailey G, Morales S, et al. Transmitted drug resistance and type of infection in newly diagnosed HIV-1 individuals in Honduras. J Clin Virol. 2010; 49:239-244. [PubMed: 20417152]

30. Balode D, Westman M, Kolupajeva T, et al. Low prevalence of transmitted drug resistance among newly diagnosed HIV-1 patients in Latvia. J Med Virol. 2010; 82:2013-2018. [PubMed: 20981787]

31. Vercauteren J, Wensing AM, van de Vijver DA, et al. Transmission of drug-resistant HIV-1 is stabilizing in Europe. J Infect Dis. 2009; 200:1503-1508. [PubMed: 19835478]

32. Eyawo O, de Walque D, Ford N, et al. HIV status in discordant couples in sub-Saharan Africa: a systematic review and meta-analysis. Lancet Infect Dis. 2010; 10:770-777. [PubMed: 20926347] 
This systematic review finds that women are as likely as men to be the index partner in a discordant couple, highlighting the need to focus on both sexes in HIV prevention strategies.

33. Trask SA, Derdeyn CA, Fideli U, et al. Molecular epidemiology of human immunodeficiency virus type 1 transmission in a heterosexual cohort of discordant couples in Zambia. J Virol. 2002; 76:397-405. [PubMed: 11739704]

34. Wawer MJ, Gray RH, Sewankambo NK, et al. Rates of HIV-1 transmission per coital act, by stage of HIV-1 infection, in Rakai, Uganda. J Infect Dis. 2005; 191:1402-1409.

35. Gray R. The contribution of HIV-discordant relationships to new HIV infections in Rakai, Uganda. AIDS. (in press). This research letter presented findings from a secondary analysis of the Rakai Cohort Study in which only a minority of new HIV infections was found to have occurred in the context of a stable HIV-discordant couple relationship.

36. Fideli US, Allen SA, Musonda R, et al. Virologic and immunologic determinants of heterosexual transmission of human immunodeficiency virus type 1 in Africa. AIDS Res Hum Retroviruses. 2001; 17:901-910. [PubMed: 11461676]

37. Quinn TC, Wawer MJ, Sewankambo N, et al. Viral load heterosexual transmission of human immunodeficiency virus type 1. Rakai Project Study Group. N Engl J Med. 2000; 342:921-929. [PubMed: 10738050]

38. Operskalski EA, Stram DO, Busch MP, et al. Role of viral load in heterosexual transmission of human immunodeficiency virus type 1 by blood transfusion recipients. Transfusion Safety Study Group. Am J Epidemiol. 1997; 146:655-661. [PubMed: 9345119]

39. Pedraza MA, del Romero J, Roldan F, et al. Heterosexual transmission of HIV-1 is associated with high plasma viral load levels and a positive viral isolation in the infected partner. J Acquir Immune Defic Syndr. 1999; 21:120-125. [PubMed: 10360803]

40. Tovanabutra S, Robison V, Wongtrakul J, et al. Male viral load and heterosexual transmission of HIV-1 subtype E in northern Thailand. J Acquir Immune Defic Syndr. 2002; 29:275-283. [PubMed: 11873077]

41. Castilla J, del Romero G, Hernando V, et al. Effectiveness of highly active antiretroviral therapy in reducing heterosexual transmission of HIV. J Acquir Immune Defic Syndr. 2005; 40:96-101. [PubMed: 16123689]

42. Del Romero J, Castilla J, Hernando V, et al. Combined antiretroviral treatment and heterosexual transmission of HIV-1: cross sectional and prospective cohort study. BMJ. 2010; 340:c2205. [PubMed: 20472675] This article reports findings from a prospective study of 424 serodiscordant couples and finds an HIV seroconversion rate of $0-0.0005$ per unprotected intercourse among the 144 couples in which the index partner was on ART. This finding suggests that heterosexual infectivity of HIV-1 in treated individuals may be very low.

43. Donnell D, Baeten JM, Kiarie J, et al. Heterosexual HIV-1 transmission after initiation of antiretroviral therapy: a prospective cohort analysis. Lancet. 2010; 375:2092-2098. [PubMed: 20537376]

44. Hernando V, del Romero G, Garcia S, et al. Reducing sexual risk behavior among steady heterosexual serodiscordant couples in a testing and counseling program. Sex Transm Dis. 2009; 36:621-628. [PubMed: 19955873]

45. Melo MG, Santos BR, Lira RDC, et al. Sexual transmission of HIV-1 among serodiscordant couples in Porto Alegre, southern Brazil. Sex Transm Dis. 2008; 35:912-915. [PubMed: 18607309]

46. Musicco M, Lazzarin A, Nicolosi A, et al. Antiretroviral treatment of men infected with human immunodeficiency virus type 1 reduces the incidence of heterosexual transmission. Italian Study Group on HIV Heterosexual Transmission. Arch Intern Med. 1994; 154:1971-1976. [PubMed: 8074601]

47. Reynolds SJ, Makumbi F, Nakigozi G, et al. HIV-1 transmission among HIV-1 discordant couples before and after the introduction of antiretroviral therapy. AIDS. 2011; 25:473-477. [PubMed: 21160416]

48. Sullivan, P.; Kayitenkore, K.; Chomba, E., et al. Reduction of HIV transmission risk and high risk sex while prescribed ART: results from discordant couples in Rwanda and Zambia; 16th Conference on Retroviruses and Opportunistic Infections; Montreal, Canada. 2009. 
49. Wang L, Ge Z, Luo J, et al. HIV transmission risk among serodiscordant couples: a retrospective study of former plasma donors in Henan, China. J Acquir Immune Defic Syndr. 2010; 55:232238. [PubMed: 21423851] This article reports findings from a prospective study of 1927 serodiscordant couples. Authors report an HIV incidence rate of 1.71 per 100 person-years in which transmission events are equally distributed among couples whose index case was receiving or was not receiving ART.

50. Bunnell R, Ekwaru JP, Solberg P, et al. Changes in sexual behavior and risk of HIV transmission after antiretroviral therapy and prevention interventions in rural Uganda. AIDS. 2006; 20:85-92. [PubMed: 16327323]

51. Das M, Chu PL, Santos GM, et al. Decreases in community viral load are accompanied by reductions in new HIV infections in San Francisco. PLoS One. 2010; 5:e11068. [PubMed: 20548786] This study identified a positive association between decreases in total community viral load - measured as the sum of the most recent viral load of all reported HIV-positive individuals and the era of expanded ART in San Francisco.

52. Katz MH, Schwarcz SK, Kellogg TA, et al. Impact of highly active antiretroviral treatment on HIV seroincidence among men who have sex with men: San Francisco. Am J Public Health. 2002; 92:388-394. [PubMed: 11867317]

53. Porco TC, Martin JN, Page-Shafer KA, et al. Decline in HIV infectivity following the introduction of highly active antiretroviral therapy. AIDS. 2004; 18:81-88. [PubMed: 15090833]

54. Fang CT, Hsu HM, Twu SJ, et al. Decreased HIV transmission after a policy of providing free access to highly active antiretroviral therapy in Taiwan. J Infect Dis. 2004; 190:879-885. [PubMed: 15295691]

55. Lima VD, Johnston K, Hogg RS, et al. Expanded access to highly active antiretroviral therapy: a potentially powerful strategy to curb the growth of the HIV epidemic. J Infect Dis. 2008; 198:5967. [PubMed: 18498241]

56. Montaner JS, Hogg R, Wood E, et al. The case for expanding access to highly active antiretroviral therapy to curb the growth of the HIV epidemic. Lancet. 2006; 368:531-536. [PubMed: 16890841]

57. Montaner JS, Lima VD, Barrios R, et al. Association of highly active antiretroviral therapy coverage, population viral load, and yearly new HIV diagnoses in British Columbia, Canada: a population-based study. Lancet. 2010; 376:532-539. [PubMed: 20638713] Using mathematical models to analyze HIV surveillance data in British Columbia, the authors of this study claimed evidence of strong population-level associations among expanded ART coverage, decreased population viral load, and fewer annual HIV diagnoses between 1996 and 2009.

58. Shelton JD, Cohen M, Barnhart M, Hallett T. Is antiretroviral therapy modifying the HIV epidemic? Lancet. 2010; 376:1824-1825. author reply 1825. [PubMed: 21111901]

59. Grulich AE, Wilson DP. Is antiretroviral therapy modifying the HIV epidemic? Lancet. 2010; 376:1824. author reply 1825. [PubMed: 21111902] The authors point out the ecologic fallacy underlying the findings by Montaner et al. [57•] on the association between ART coverage and community HIV viral load. Safer injection practices among IDUs is also highlighted as a likely confounder that could lead to overestimation of the association between expanded ART on lowered HIV incidence in British Columbia.

60. Dukers NHTM, Spaargaren J, Geskus RB, et al. HIV incidence on the increase among homosexual men attending an Amsterdam sexually transmitted disease clinic: using a novel approach for detecting recent infections. AIDS. 2002; 16:F19-F24. [PubMed: 12131206]

61. Stolte IG, Dukers NHTM, de Wit JBF, et al. Increase in sexually transmitted infections among homosexual men in Amsterdam in relation to HAART. Sex Transm Infect. 2001; 77:184-186. [PubMed: 11402225]

62. Jansen IA, Geskus RB, Davidovich U, et al. Ongoing HIV-1 transmission among men who have sex with men in Amsterdam: a 25-year prospective cohort study. AIDS. 2011; 25:493-501. [PubMed: 21192230] This cohort study reports ongoing HIV-1 transmission among MSM in Amsterdam, particularly following increases in sexual risk behavior from 1996 onwards.

63. Jin F, Jansson J, Law M. Per-contact probability of HIV transmission in homosexual men in Sydney during the era of HAART. AIDS. 2010; 24:907-913. [PubMed: 20139750] A longitudinal cohort study of homosexual men in Australia found little difference in the per-contact probability 
of HIV transmission before and after widespread uptake of ART in HIV-infected men. The authors hypothesize that untreated STIs or unprotected sex during acute infection may partially explain the persistence of transmission even with high ART coverage.

64. Lima, V.; Williams, B.; Hogg, R., et al. Why the MSM-driven HIV epidemic is not slowing down even in the presence of HAART; 18th Conference on Retroviruses and Opportunistic Infections; Boston, Massachusetts. 2011.

65. Hall HI, Song R, Rhodes P, et al. Estimation of HIV incidence in the United States. JAMA. 2008; 300:520-529. [PubMed: 18677024]

66. Le Vu S, Le Strat Y, Barin F, et al. Population-based HIV-1 incidence in France, 2003-08: a modelling analysis. Lancet Infect Dis. 2010; 10:682-687. [PubMed: 20832367] This analysis uses a stratified extrapolation model to estimate population incidence of HIV in France. Findings suggest that overall incidence in France is decreasing, but remains comparatively high among MSM.

67. Cohen MS, Gay CL. Treatment to prevent transmission of HIV-1. Clin Infect Dis. 2010; 50(Suppl 3):S85-S95. [PubMed: 20397961]

68. Wilson DP, Garnett GP. Introduction to recent developments in HIV epidemic modeling. Curr Opin HIV AIDS. 2011; 6:91-93. [PubMed: 21505381]

69. Cambiano V, Phillips AN. Modelling the impact of treatment with individual antiretrovirals. Curr Opin HIV AIDS. 2011; 6:124-130. [PubMed: 21505387]

70. Granich RM, Gilks CF, Dye C, et al. Universal voluntary HIV testing with immediate antiretroviral therapy as a strategy for elimination of HIV transmission: a mathematical model. Lancet. 2009; 373:48-57. [PubMed: 19038438]

71. Wilson DP, Law MG, Grulich AE, et al. Relation between HIV viral load and infectiousness: a model-based analysis. Lancet. 2008; 372:314-320. [PubMed: 18657710]

72. Law MG, Prestage G, Grulich A, et al. Modelling the effect of combination antiretroviral treatments on HIV incidence. AIDS. 2001; 15:1287-1294. [PubMed: 11426074]

73. Pretorius C, Stover J, Bollinger L, et al. Evaluating the cost-effectiveness of preexposure prophylaxis (PrEP) and its impact on HIV-1 transmission in South Africa. PLoS One. 2010; 5:e13646. [PubMed: 21079767] This study models the potential impact of pre-exposure prophylaxis in averting new infections in South Africa and estimates a range in cost from \$1 2500 to $\$ 20000$ per infection averted, depending on the level of ART coverage and baseline incidence.

74. Walensky RP, Paltiel AD, Losina E, et al. Test and treat DC: forecasting the impact of a comprehensive HIV strategy in Washington DC. Clin Infect Dis. 2010; 51:392-400. [PubMed: 20617921] This study applies a mathematical model to estimate the potential impact of an expanded HIV test and treat program in Washington, District of Columbia. The authors find that an intensive test and treat program - although expected to yield substantial benefits to individual patients - cannot be expected to stop the epidemic in Washington, District of Columbia, a finding that holds important implications for ongoing 'test and treat' strategies.

75. Long EF, Brandeau ML, Owens DK. The cost-effectiveness and population outcomes of expanded HIV screening and antiretroviral treatment in the United States. Ann Intern Med. 2010; 153:778789. [PubMed: 21173412] This article applies a dynamic mathematical model to perform a costeffectiveness model of expanded ART, HIV screening, and behavioral interventions. The authors suggest that expanded screening and treatment offers a substantial public health impact, but are insufficient to reduce the US HIV epidemic without substantial reductions in risk behavior.

76. World Health Organization. Antiretroviral therapy for HIV infection in adults and adolescents: recommendations for a public health approach. 2010 revision. Geneva: WHO Press; 2010. http:// whqlibdoc.who.int/publications/2010/9789241599764_eng.pdf. [Accessed 19 February 2011]

77. Emery S, Neuhaus JA, Phillips AN, et al. Major clinical outcomes in antiretroviral therapy (ART)naive participants and in those not receiving ART at baseline in the SMART study. J Infect Dis. 2008; 197:1133-1144. [PubMed: 18476292]

78. Severe, P.; Pape, J.; Fitzgerald, DW. A randomized clinical trial of early versus standard antiretroviral therapy for HIV-infected patients with a CD4 T cell count of 200-350 cells $/ \mathrm{ml}$ (CIPRA HT 001); 49th Interscience Conference on Antimicrobial Agents and Chemotherapy; San Francisco, California. 2009. 
79. Vernazza P, Hirschel B, Bernasconi E, Flepp M. HIV - infected patients under HAART without any other sexually transmitted infection do not transmit HIV by sexual intercourse. Bull Med Suisse. 2008; 89:165-169.

80. Hasse B, Ledergerber B, Hirschel B, et al. Frequency and determinants of unprotected sex among HIV-infected persons: the Swiss HIV cohort study. Clin Infect Dis. 2010; 51:1314-1322. [PubMed: 21034200]

81. Cohen MS. HIV treatment as prevention and 'The Swiss Statement': in for a dime, in for a dollar? Clin Infect Dis. 2010; 51:1323-1324. [PubMed: 21034196]

82. Novitsky V, Wang R, Bussmann H, et al. HIV-1 subtype C-infected individuals maintaining high viral load as potential targets for the 'test-and-treat' approach to reduce HIV transmission. PLoS One. 2010; 5:e10148. [PubMed: 20405044]

83. Dyer JR, Kazembe P, Vernazza PL, et al. High levels of human immunodeficiency virus type 1 in blood and semen of seropositive men in sub-Saharan Africa. J Infect Dis. 1998; 177:1742-1746. [PubMed: 9607862]

84. Ping LH, Nelson JAE, Hoffman IF, et al. Characterization of V3 sequence heterogeneity in subtype $\mathrm{C}$ human immunodeficiency virus type 1 isolates from Malawi: underrepresentation of X4 variants. J Virol. 1999; 73:6271-6281. [PubMed: 10400718]

85. Miller WC, Rosenberg NE, Rutstein SE, Powers KA. Role of acute and early HIV infection in the sexual transmission of HIV. Curr Opin HIV AIDS. 2010; 5:277-282. [PubMed: 20543601]

86. Koopman JS, Jacquez JA, Welch GW, et al. The role of early HIV infection in the spread of HIV through populations. J Acquir Immune Defic Syndr Hum Retroviral. 1997; 14:249-258.

87. Hollingsworth TD, Anderson RM, Fraser C. HIV-1 transmission, by stage of infection. J Infect Dis. 2008; 198:687-693. [PubMed: 18662132]

88. Powers, K.; Ghani, A.; Miller, W., et al. The contribution of early HIV infection to HIV spread in Lilongwe, Malawi: implications for transmission prevention strategies; International AIDS Conference; Vienna. 2010. abstract FRLBC105, 2010

89. Hightow LB, MacDonald PD, Pilcher CD, et al. The unexpected movement of the HIV epidemic in the southeastern United States: transmission among college students. J Acquir Immune Defic Syndr. 2005; 38:531-537. [PubMed: 15793362]

90. Pettifor A, Macphail C, Corneli A, et al. Continued high risk sexual behavior following diagnosis with acute HIV infection in South Africa and Malawi: implications for prevention. AIDS Behav. (in press).

91. Cohen MS, Shaw G, Haynes B, McMicael A. Acute HIV infection: basic, clinical and public health perspectives. New Engl J Med. 2011 Forthcoming. 


\section{Key points}

- Antiretroviral therapy (ART) will serve as a cornerstone of combination prevention of HIV-1.

- Critical areas of scientific research must improve our understanding of drug penetration into the genital tract and the risk of transmitted drug resistance.

- Implementation challenges remain in finding the most contagious people and treating them optimally during the early disease stages.

- Observational data, mathematical models, and ecological studies provide seemingly compelling evidence of ART's preventive effects, but are subject to many limitations. 


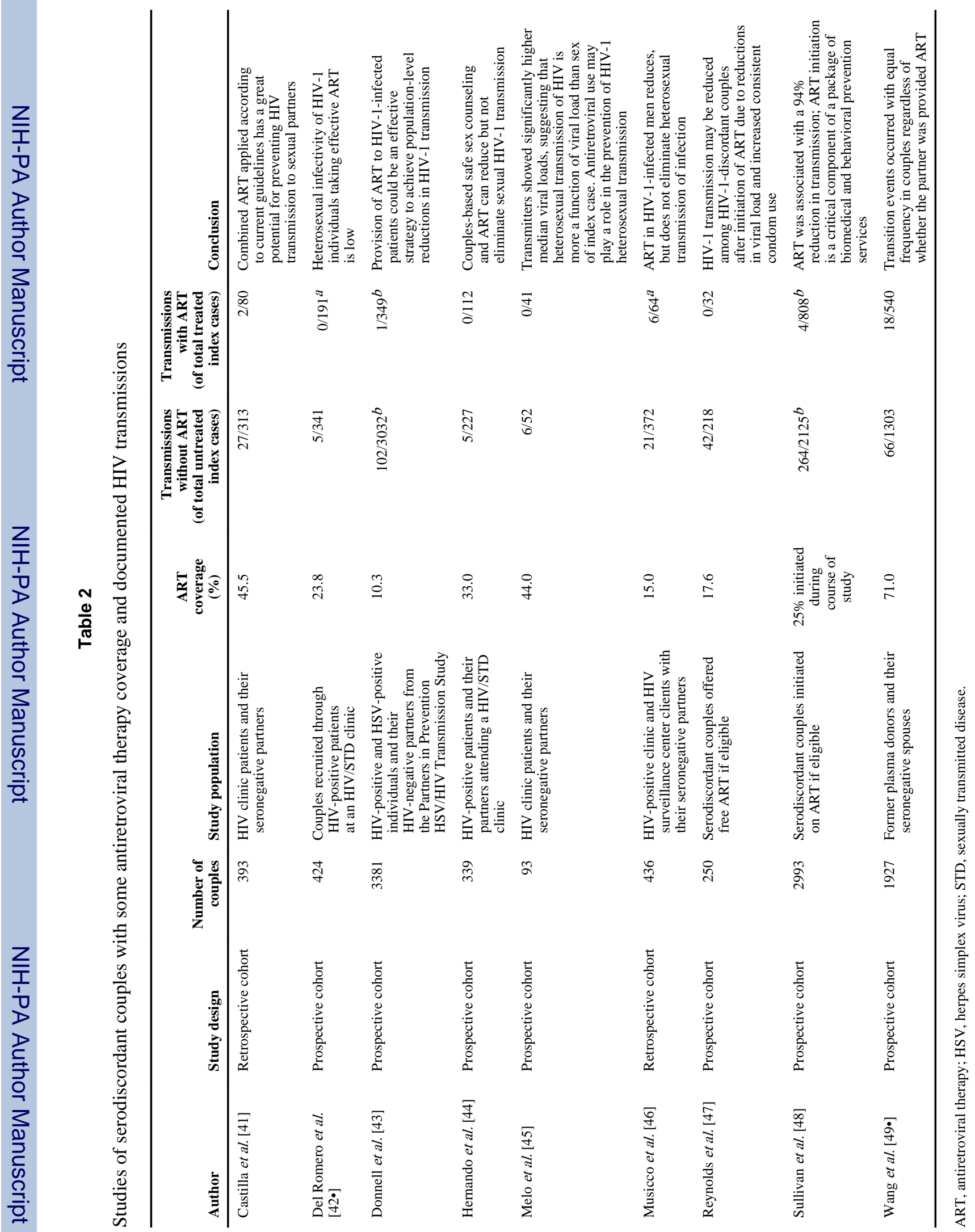




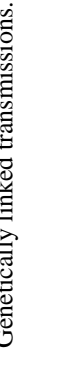


Table 3

Planned and ongoing 'test and treat' feasibility studies

\begin{tabular}{|c|c|c|c|c|}
\hline Project title & Principal investigator(s) & Source of funding & Study site (features) & Progress \\
\hline $\begin{array}{l}\text { Population effects of } \\
\text { Antiretroviral } \\
\text { Therapy (Pop-ART) }\end{array}$ & $\begin{array}{l}\text { Sarah Fidler, Department of } \\
\text { Medicine, } \\
\text { Imperial College }\end{array}$ & $\begin{array}{l}\text { Medical Research } \\
\text { Council, UK }\end{array}$ & $\begin{array}{l}\text { Africa (scale-up of ART } \\
\text { for } \\
\text { all HIV-positive adults } \\
\text { and } \\
\text { expansion of VCT and } \\
\text { ART } \\
\text { access to reduce HIV } \\
\text { transmission) }\end{array}$ & Funding pending \\
\hline $\begin{array}{l}\text { Methods for Prevention Package } \\
\text { Program (MP3): 'PreventionRx' }\end{array}$ & $\begin{array}{l}\text { Connie Celum, Department } \\
\text { of Global } \\
\text { Health, International } \\
\text { Clinical Research } \\
\text { Center, University of } \\
\text { Washington }\end{array}$ & $\begin{array}{l}\text { National Institute of } \\
\text { Allergy and } \\
\text { Infectious Disease, } \\
\text { USA }\end{array}$ & $\begin{array}{l}\text { Uganda (efficacy trial of a } \\
\text { multicomponent HIV } \\
\text { prevention package in } \\
\text { behaviorally at-risk } \\
\text { individuals } \\
\text { and serodiscordant } \\
\text { couples) }\end{array}$ & $\begin{array}{l}\text { Field activities to } \\
\text { be initiated } \\
\text { in mid-2010 }\end{array}$ \\
\hline $\begin{array}{l}\text { Methods for Prevention Package } \\
\text { Program (MP3): 'Enhanced } \\
\text { Prevention in Couples' (EPIC) }\end{array}$ & $\begin{array}{l}\text { Wafaa El-Sadr, Center for } \\
\text { Infectious } \\
\text { Disease Epidemiologic } \\
\text { Research at } \\
\text { Mailman School of Public } \\
\text { Health }\end{array}$ & $\begin{array}{l}\text { National Institute of } \\
\text { Allergy and } \\
\text { Infectious Disease, } \\
\text { USA }\end{array}$ & $\begin{array}{l}\text { Lesotho (feasibility study } \\
\text { of a } \\
\text { prevention package } \\
\text { including } \\
\text { early ART initiation, } \\
\text { male } \\
\text { circumcision, and } \\
\text { behavioral counseling) }\end{array}$ & Study ongoing \\
\hline $\begin{array}{l}\text { Botswana-Harvard Partnership } \\
\text { Study Series }\end{array}$ & $\begin{array}{l}\text { Max Essex, Harvard School } \\
\text { of Public } \\
\text { Health AIDS Initiative }\end{array}$ & & $\begin{array}{l}\text { Botswana (targeted } \\
\text { treatment } \\
\text { program for HIV-infected } \\
\text { individuals at greatest } \\
\text { risk of } \\
\text { transmitting HIV) }\end{array}$ & Study ongoing \\
\hline $\begin{array}{l}\text { Makerere University-University } \\
\text { of } \\
\text { California San Francisco } \\
\text { Research } \\
\text { Collaboration }\end{array}$ & $\begin{array}{l}\text { Diane Havler, HIV/AIDS } \\
\text { Division and } \\
\text { Positive Health Program at } \\
\text { San } \\
\text { Francisco General Hospital }\end{array}$ & & $\begin{array}{l}\text { East Africa (project to } \\
\text { identify } \\
\text { sustainable methods to } \\
\text { treat } \\
\text { HIV earlier to benefit } \\
\text { overall } \\
\text { health, education, and } \\
\text { economics } \\
\text { in East Africa) }\end{array}$ & Conceptual stages \\
\hline $\begin{array}{l}\text { HIV Prevention Trials Network } \\
\text { 065: } \\
\text { Test and Link to Care-Plus } \\
\text { (TLC-Plus) }\end{array}$ & $\begin{array}{l}\text { Wafaa El-Sadr, Center for } \\
\text { Infectious } \\
\text { Disease Epidemiologic } \\
\text { Research at } \\
\text { Mailman School of Public } \\
\text { Health }\end{array}$ & $\begin{array}{l}\text { National Institute of } \\
\text { Allergy and } \\
\text { Infectious Disease, } \\
\text { USA }\end{array}$ & $\begin{array}{l}\text { USA (a study to evaluate } \\
\text { feasibility } \\
\text { of an enhanced test and } \\
\text { link to } \\
\text { care along with treatment } \\
\text { approach for HIV } \\
\text { prevention) }\end{array}$ & Protocol pending \\
\hline Treatment as Prevention (TasP) & $\begin{array}{l}\text { Marie-Louise Newell, Africa } \\
\text { Centre for } \\
\text { Health and Population } \\
\text { Studies, } \\
\text { University of KwaZulu- } \\
\text { Natal; François } \\
\text { Dabis, University of } \\
\text { Bordeaux, France }\end{array}$ & $\begin{array}{l}\text { French Agency for } \\
\text { Research on } \\
\text { HIV/AIDS and } \\
\text { Viral Hepatitis, } \\
\text { France }\end{array}$ & $\begin{array}{l}\text { South Africa (cluster } \\
\text { randomized trial } \\
\text { of early versus delayed } \\
\text { ART } \\
\text { initiation for HIV- } \\
\text { infected individuals) }\end{array}$ & $\begin{array}{l}\text { Initial phase to } \\
\text { begin in } 2011\end{array}$ \\
\hline
\end{tabular}

Minutes from a self-organized meeting of all principal investigators (or a knowledgeable colleague) at the 18th Annual Conference on Retroviruses and Opportunistic Infections; 2011; Boston, Massachusetts. Courtesy of Sten Vermund, Vanderbilt University School of Medicine. ART, antiretroviral therapy; VCT, voluntary testing and counseling. 